\title{
O JARDIM IMEMORIAL. AS FLORES DO MAL E AS \\ FORMAS PRIMORDIAIS DA ARTE
}

\section{Susana Scramim}

(BENJAMIN, Walter. "Paris do Segundo Império". Charles Baudelaire. Um lírico no auge do capitalismo. São Paulo: Brasiliense, 1994: 21.)
Baudelaire era um admirador dos jesuítas, segundo Walter Benjamin, que também o era. No texto "Paris do Segundo Império", Benjamin considera que na França cindida do final do século XIX coexistiam o cinismo da classe alta e a argumentação rebelde da baixa, os quais se materializavam na recorrente valorização por parte de alguns artistas da figura ambivalente de Lúcifer, isto é, o anjo rebelde das massas coexistindo com o ambicioso dirigente da marcha corrupta em direção ao poder. Benjamin sublinha que

essa dupla face de Satã é, de ponta a ponta, familiar a Baudelaire. Para ele, Satã não fala apenas pelos inferiores, mas também pelos superiores. Dificilmente, Marx teria podido encontrar um leitor melhor para as seguintes linhas: "Quando os puritanos - diz em $O$ Dezoito Brumário - protestavam contra a vida depravada dos papas..., o cardeal Pierre D'Aill trovejou contra eles: - Só o Diabo em pessoa ainda pode salvar a Igreja católica, e vós exigis anjos! - Assim bradava a burguesia francesa após o golpe de Estado - Só o líder da Sociedade de 10 de Dezembro ainda pode salvar a sociedade burguesa! Só o roubo à propriedade, o perjúrio à religião, a bastardia à família, a desordem à ordem!”. Mesmo em suas horas mais rebeldes não quis Baudelaire, admirador dos jesuítas, romper de todo e para sempre com esse salvador".

Baudelaire é afetado por esse Satâ, pois em sua obra há um movimento de ir e vir de um estado de anjo rebelde ao de grande corruptor do discernimento e da humanidade. Esse "afecto" não somente indica a natureza do corpo afetado, envolvendo apenas a natureza do corpo afetante, mas é um efeito de passagem e variação contínuas da potência, que vão de um corpo ao outro, nesse caso, do corpo do poema à corporificação do Mal. Em "O Heautontimoroumenos", incluído no ciclo "Spleen e ideal", esse afeto por Satã toma a forma de uma equiparação entre ser a "faca e o talho", o "rosto e a bofetada", a "vítima e o algoz". Benjamin, ainda em "Paris do Segundo Império", comenta o poema "As Litanias de Satâ", situado no ciclo intitulado "A revolta", e vê nele o conteúdo mitológico de uma mitologia ofídica, isto é, uma seita gnóstica do século II, que fazia da serpente adorada um símbolo do messias, da 
mesma forma que entrevê no Satã, caracterizado como uma divindade de sapiência luciferina, a cabeça sombria de Blanqui.

[...]

Glória e louvor a ti, Satã, lá nas alturas

Do Céu, onde reinaste, e nas furnas escuras

Do Inferno, onde, vencido, sonhas silencioso!

Sob a Árvore da Ciência, um dia, que o repouso

Minha alma encontre em ti, quando na tua testa

Seus ramos expandir qual novo Templo em festa!*

Podemos também perceber nessa análise de Benjamin vestígios de sua concepção de linguagem do drama barroco, elaborada a partir de 1923. Quando Benjamin se refere às antinomias do "alegorês", já detecta uma ambivalência entre convenção e expressão, que brota da tentativa alegórica de expressar a decadência da história natural combinada com a convenção histórica. A convenção impõe a expressão da história cultural num rosto, numa fisionomia; a combinação dessa convenção histórica com a história natural, portanto, em seu "vir-a-ser" e extinguir-se, permite a expressão da história humana como declínio da convenção através de uma "protopaisagem" petrificada. ${ }^{1}$ Baudelaire teria compreendido, no seu "As Litanias de Satã", essa possibilidade combinatória entre serpente/ Satã/ Blanqui. Tal problema torna-se ainda mais interessante se retornamos a outro fragmento de Origem do Drama Barroco Alemão, justamente aquele, intitulado "Terrores e promessas de Satã”. Ali, Benjamin ressalta que

a concepção alegórica tem sua origem no contraste entre uma physis culpada [...] e uma natura deorum mais pura [...]. Na medida em que a Renascença renova o elemento pagão, e a Contra-Reforma o elemento cristão, a alegoria precisa também renovar-se, como forma de sua confrontação. O importante, para o drama barroco, é que a Idade Média ligou indissoluvelmente o material e o demoníaco. [...] A matéria, que segundo a doutrina gnóstico-maniqueísta, havia sido criada para promover a "destartarização" do mundo absorvendo em si o diabólico, para que, com sua eliminação, o mundo pudesse se apresentar purificado, lembra-se, através do diabo, de sua natureza "tartárica”, zomba de sua significação "alegóri-

\footnotetext{
${ }^{1} \mathrm{O}$ fóssil como imagem da história é potência contida de provocar as emoçôes, uma versão profana e secularizada do "Natura naturans" (poder de criar) e do "natura naturata" (a coisa criada) que nos chega desde Aristóteles, passando por Averróis até Spinoza.
}

' (BAUdelaiRe, Charles. As flores do mal. Tradução Ivan Junqueira. Rio de Janeiro: Editora Nova Fronteira, 1985: 427.) 
(Benjamin, W. Origem do drama barroco alemão, tradução Sérgio Paulo Rouanet. São Paulo: Brasiliense. 1984: 250.)

- (BAUDELAIRE, C. As flores do mal. Op. cit.: 425 .) ca” e escarnece de todos aqueles que imaginam poder investigá-la, impunemente, em sua profundidade. [...] Daí a jovialidade infernal do intrigante, seu intelectualismo, o saber das significaçóes, de que ele dispóe."

Por isso, o refrão da litania, é a súplica baudelairiana:

“Tem piedade, ó Satã, de minha atroz miséria."*

Nesse sentido, a mercadoria moderna só poderia mesmo estar associada, no poema de Baudelaire, a Satã, e mais, ao mal. A nova linguagem, a linguagem da modernidade, da mercadoria, tão imprescindível para a criação, para o novo Adão, nunca proporciona ao poeta a chave do virtual. Para sair de sua mudez, de seu silêncio, o poeta precisará chegar mais perto da matéria, das coisas, portanto, do diabo; porém, visto de uma outra forma, esse movimento em direção a uma nova linguagem, se pauta pela concepção de alegoria na qual se combina a idéia de decadência pertencente à história natural com a idéia do movimento operado pela convenção histórica.

No entanto, se o processo alegórico traz em seu cerne uma concepção mítico-religiosa, ele está cativo de uma visão secularizada da história, isto é, participa da apostasia coletiva de qualquer crença escatológica ou positiva que pudesse justificar o sofrimento terrestre como caminho para certa finalidade suprema e a última liberação. Por conseqüência, é aqui que a metáfora deixa de ser a invenção de alguma mente genial que fosse capaz de relacionar as realidades mais diversas, tal como ela costuma ser lida, para desmistificar-se e obter sua forma de ruína, ou seja, produto da linguagem em seu estado de decomposição. A concepção de história, presente nos poemas do livro As flores do mal, está intimamente relacionada a uma concepção de tempo que se situa entre a culpa ou dependência e a autonomia ou a soberba de Satá. Benjamin, ainda em "Terrores e promessas de Satâ", ressalta que o modo mais autêntico de existência do Mal não está na ação, mas no saber que reside na matéria, na investigação sobre a natureza das coisas, paixão essa, típica do barroco, mas que "pervive" em períodos posteriores ao século XVII. Experimentando o Mal, o estado de espírito que predomina é o luto; dele derivando as três promessas originais de Satã que se manifestam ora na figura do tirano ora na do intrigante: a ilusão de liberdade, a ilusão da autonomia e a ilusão do infinito. E não são estas as ilusões com as quais o poeta 
da modernidade tem que lidar no final do século XIX, bem como no século seguinte?

O poeta, porém, é afetado por essas promessas, inclusive, assumindo sua miséria frente a Satã. Sua miséria de não saber, sua miséria diante de sua impotência para o Mal. Sua impotência para a não-ação, para sua impotência de "ser-não". ${ }^{2}$ Giorgio Agamben assinala, em seu ensaio sobre a destruição da experiência, que o mundo cristão medieval estava governado por um princípio que afirmava que, "antes do pecado original, o homem conhecia o bem e o mal: o bem por experiência (per experientiam), o mal por ciência (per scientiam). No entanto, depois do pecado, o homem conhece o Mal por experiência, e o Bem somente por ciência." Por isso, a função da alegoria barroca, segundo Benjamin, será a de "não-ser" aquilo que ela é; os vícios são alegorias e somente têm existência sob o olhar subjetivo do melancólico. A alegoria expressa a indecisão do soberano e do intrigante barrocos, imagem do humano após a queda, que não consegue mais fazer experiência nem para saber do Bem, já que ele deveria decorrer de uma prática, e tampouco para saber do Mal, uma vez que ele depende de um olhar subjetivo e resulta da contemplação. Na verdade, o fracasso da alegoria barroca já indica, no século XVII, a impossibilidade de produzir saber, como resultante do pecado original e, numa visão secularizada, impotência resultante das promessas da modernidade. No entanto, esse problema ontológico é resolvido na obra de arte barroca com a idéia aristotélica do assombro, "a expressão artística do milagre". *Walter Benjamin nos diz "que não há nenhuma passagem que o estilo barroco não conclua com um milagre." Alguns teólogos do barroco se posicionaram frente a esse enfrentamento com uma produção, ao mesmo tempo, fruto de uma prática e também decorrente da ação contemplativa: a poesia-pensamento. San Juan de la Cruz se valeu das agudezas, que é um artifício "conceptuoso", o qual consiste numa primorosa concordância, entre dois ou três cognitivos extremos, expressa por um ato de entendimento, ${ }^{3}$

\footnotetext{
${ }^{2}$ Conforme o conceito de dynamis analisado por Aristóteles e comentado por Giorgio Agamben no qual o ter uma potência possui a forma de uma privação, mas que não se resume a uma simples ausência. Cf. Giorgio Agamben "A potência do pensamento", tradução Carolina Pizzolo Torquato, em Revista do Departamento de Psicologia da Universidade Federal Fluminense. ISSN 0104-8023, vol.18, no.1, Niterói, Jan./Junho, 2006.

${ }^{3}$ Baltazar Gracian define a agudeza como procedimento para produzir a beleza pela retórica, que era uma forma de aliar conhecimento e encanto; a agudeza correlaciona elementos conhecíveis extremos e produz com isso um saber. Cf. Agudeza y arte de ingenio, Livro I. Madrid: Editorial Castalia, 2001: 55.
}

- (AGAMBEN, Giorgio. Infância e História. Tradução de Silvio Mattoni. Buenos Aires: Adriana Hidalgo, 2001: 34.)

*(BENJAMIN, W. Origem do drama barroco alemão. Op. cit.: 257.)

"(Idem.) 
- (CRUZ, Juan de la. Em: SPITZER, Leo. Três poemas sobre o êxtase. Rio de Janeiro: Cosac\&Naify, 2003: 21.) praticadas pela poesia do barroco, e não dispensou os oxímoros das "figuras e similitudes extravagantes", com o intuito de produzir um saber. No poema, "En una noche oscura", lemos na tradução de Carlito Azevedo:

E tal luz me guiava,

Mais reto do que a luz do meio-dia,

Aonde me esperava

Quem eu bem conhecia,

Ali onde ninguém aparecia.

Com sua figura de "en una noche oscura", o poema elaborou um saber, pautado por um paradoxo, que pressupōe uma experiência de conhecimento de Deus puramente negativa, de uma presença que não se distingue de uma ausência e que aponta para uma natureza incognoscível ou pelo menos conhecível apenas por opacidade e negação, resultando em um saber que era um não-saber. Giorgio Agamben chama a atenção para o débito que a experiência com o negativo em Bataille, francamente assumida pelo autor francês em sua Somme athéologique, tem para com a teologia de San Juan. Esse débito não se limitaria à franca relação entre a "nudité souveraine" e a "suma desnudez" de San Juan, e tampouco se encerra com a relação entre "non-savoir" e o "no saber". Agamben assinala que Bataille leva às últimas consequiências o método de "en la noche oscura", mas sem a substituição da coisa possuída pela "despossessão", do mesmo modo que não há redenção, como é o caso da suma "desnudez" de Juan de la Cruz, já que Bataille buscaria com sua negatividade absoluta uma negatividade sem emprego. ${ }^{4}$ Esse Bataille da negatividade sem emprego irá defender a opção o pelo Mal de Baudelaire como um modo de produzir uma forma poética impessoal. A defesa é contra a análise que Sartre faz de Baudelaire, em 1946, na qual se afirma que o Mal naquela poesia era uma estratégia para se chegar ao Bem. Se assim fosse, a poesia de Baudelaire somente poderia ser lida como transgressiva, po-

\footnotetext{
${ }^{4}$ Giorgio Agamben ainda comenta, nessa mesma nota escrita no prefácio à tradução italiana dos poemas de San Juan, operada pelo próprio Agamben, que Bataille rompe com a teologia positiva e com a noção mesma de Deus, para assim aceder a esta absoluta obscuridade e, com isso, sendo conduzido a incluir na sua experiência interior também a opacidade do mal, que Juan de la Cruz menciona explicitamente como potência ofuscante, mas não incluída na experiência mística. Cf. Giorgio Agamben. "La notte oscura de Juan de la Cruz", in Juan de la Cruz, Poesie, traduzione de Giorgio Agamben. Torino: Einaudi, 1974: VII.
} 
rém, ainda utópica, uma vez que decide por um único caminho para a experiência, ou seja, uma prática que produz um saber, a prática como instância restauradora da natureza caída. Nesse sentido, ter a consciência do Mal praticado é um meio para chegar a uma finalidade: a redenção ou, em termos laicos, a destruição do sistema que transforma o mundo em mercadoria, conhecer o Mal apenas por ciência (per scientiam).

O jesuíta Baltazar Gracián, peça fundamental no estudo de Walter Benjamin sobre o barroco, ${ }^{5}$ resgatou o uso da agudeza no século XVII reivindicando para ela a função de produzir no discurso a experiência prática da Beleza como um caminho inexorável

${ }^{5}$ As indicaçôes de que Walter Benjamin admirava o trabalho do jesuíta Baltazar Gracián não se restringem apenas ao fato de que uma das formas das agudezas compiladas e estabelecidas por Gracián, a saber, "la ponderación misteriosa”, seja o título de um dos fragmentos do livro de Benjamin sobre o barroco, bem como não se limita à referência à passagem de Gracián na qual este mostra a rigidez à qual o papel do tirano dramático estava submetido, isto é, necessariamente submetida ao estereótipo e ao exagero, ao comentar as paródias feitas nos dramas barrocos vienenses quando do tratamento dado aos tiranos em alguns dramas. Interessante ressaltar que para corroborar seu projeto de fazer aparecer a relação entre indecisão soberana, índice da crise da transcendência na história, com o abandono da forma clássica trágica e a opção estética pelo drama. Por sua modelagem retórica, orientada pelos manuais do jesuíta Baltazar Gracián, a estrutura do drama deixava aparecer essa grande cisão dentro projeto racionalista. Não consta que Benjamin tenha lido Baltazar Gracián em castelhano; aliás, no livro Origem do drama barroco, a obra de Gracián El politico don Fernando el Católico (1640) aparece citada a partir de uma tradução publicada em Bresslau, em 1676, creditada a Daniel Caspern von Lohenstein, um desses obscuros dramaturgos da escola de Silesia aos quais o livro de Benjamin se dedica. Sabemos, conforme o próprio autor atesta na dedicatória de Origem do drama barroco alemão, que Benjamin esteve trabalhando no livro sobre o barroco desde 1916 até a sua redação final em 1925. Nesse mesmo momento, Walter Benjamin está também traduzindo alguns poemas de Baudelaire para o alemão, segundo o estudo de $\mathrm{Su}$ sana Kampf Lages apresentado neste mesmo colóquio As flores do mal: 150 anos. Dessa forma, podemos dizer que o estudo sobre o barroco e a leitura da obra de Baudelaire, ambas, tanto o barroco como a obra de Baudelaire, prenhes da constatação da cisão ambivalente entre perda da transcendência e abandono da forma clássica, fornecerão as formas primordiais com as quais Benjamin elaborará sua leitura da modernidade desenvolvida a partir de 1930. Podemos ainda constatar que na correspondência com Gretel Karplus, esposa de Adorno, Benjamin tinha a intenção de escrever um estudo sobre Gracían e, um ano após ter declarado sua intenção à amiga, portanto, em 1933, Benjamin lhe presenteara com um exemplar do Oráculo Manual, traduzido ao alemão por Shopenhauer (Cf. Gesammelte Briefe. Band IV (1931-1934). Herausgegeben von Christoph Gödde und Henri Lonitz. Frankfurt am Main: 1998), assim como o ensaio de Susana Kampf Lages publicado neste volume. Agradeço em especial sobre essas questôes os diálogos e as informações com os quais generosamente me brindaram Raúl Antelo e Georg Otte. 
- (GRACIÁN, B. Agudeza y arte de ingenio. Madrid: Editorial Castalia, 2001: 49.)

•(Idem.)

*(Idem: 55.)

* (GRACIÁN, Baltazar. Agudeza y arte de ingenio. Op. cit.: p. 89). para o conhecimento. ${ }^{*}$ A agudeza produz uma beleza aguda, afiada como uma espada. Ainda é interessante ressaltar que Gracián diz que a produção da agudeza é trabalho de um anjo, e que o discurso agudo, além situar-se nesse campo conceitual teológico, encontra-se envolvido no conceito de que a palavra, o gesto e inclusive o silêncio são entendidos como uma arma e o homem de letras como um combatente, um guerreiro, um herói. Um herói que luta para produzir atos de entendimento, de conhecimento ativo, que exprimam a correspondência que se encontra entre os objetos. ${ }^{*}$ No entanto, de que tipo de conhecimento se trata? Retomemos Walter Benjamin. No último e enigmático fragmento do livro Origem do drama barroco alemão, intitulado, "Ponderación Misteriosa", no qual o autor defende a monstruosidade antiartística do barroco que converge no "Mal-em-si" da figura alegórica, Benjamin descreve o movimento executado na obra barroca: um milagre flutuante traz de volta pelas alegorias o anjo caído e o fixa no céu pela "ponderación misteriosa". E o movimento será iniciado novamente quando esse anjo, que é ninguém menos que Lúcifer, com o qual tanto a plebe quanto os dirigentes da Paris do Segundo Império se identificam, voltar a cair. A "ponderación misteriosa" é uma das formas da agudeza tratadas por Gracián em seu Agudeza y arte de ingenio:

Quien dice misterio, dice preñez, [...] Las contingencias son la ordinaria materia de los misterios [...] Fúndase el misterio tanto en lo positivo como en lo negativo de las circunstancias, y hácese el reparo, así en la que concurre como en la que faltó, si bien es menester más fundamento cuando se forma por carencia."

O milagre na obra barroca resgata e ao mesmo tempo impede a experiência do saber prático porque o anjo melancólico volta a cair. Portanto, não se trata do conhecimento prático, mas antes de um saber ativo.

Todos nós sabemos que a experiência do choque é fundamental para a poética de Baudelaire, poderíamos até mesmo dizer que o choque nessa poética é um saber primário, isto é, resulta da contemplação. Christine Buci-Glucksman ressalta em La raison baroque, publicado pela primeira vez em 1984, que o choque põe o sujeito em relação com o desconhecido, mas que essa relação não pode ser mais compreendida como religiosa nem tradicional. Entretanto, a crítica francesa ainda compreende o problema da experiência em Baudelaire como uma experiência pessoal, como uma prática que produz um novo saber, pois para Christine Buci-Glu- 
cksman, diferentemente do barroco, no qual a morte e o abismo estariam exteriorizados, no "spleen" baudelairiano a morte é interiorizada; e a autora completa sua análise com a seguinte observação: "A alegoria barroca não vê o cadáver a não ser de seu exterior. Baudelaire a vê do interior." $6^{*}$ Questão essa que ela irá retomar de maneira diferente no livro Au-delà de la mélancolie, publicado em 2005. De outra parte, não devemos esquecer de relacionar aquilo que Benjamin percebeu na fórmula aristotélica do assombro, isto é, a forma artística do milagre no drama barroco, com aquilo que, no ensaio sobre Baudelaire, ele detecta como uma proporcionalidade entre a maior incidência do choque e a menor produção de experiência e a maior produção de vivência, portanto, o choque produziria um saber secundário porque decorre de uma prática. Benjamin anota, em diapasão gracianesco: "Baudelaire abraçou como sua causa aparar os choques, de onde quer que proviessem, com o seu ser espiritual e físico. A esgrima representa a imagem dessa resistência ao choque." " Giorgio Agamben nos diz, já em 1977, no libro Estancias que o choque em Baudelaire ${ }^{7}$

es el potencial de extrañamiento de que se cargan los objetos cuando pierden la autoridad que deriva de su valor de uso y que garantiza su inteligibilidad tradicional, para asumir la máscara enigmática de la mercancía. [...] de este modo [el choc] habría logrado hacer de la obra vehículo mismo de lo inasible y restaurar en la inasibilidad misma un nuevo valor y una nueva autoridad.

Essa perda de um saber prático da poesia recoloca o problema da experiência como algo que produz um saber primário, um saber negativo, portanto um saber da falta. É o próprio Agamben que, posteriormente, em 1978, no seu ensaio sobre a destruição da experiência, irá dizer que o choque pressupõe sempre uma falha na experiência, pois conhecer algo implica tirar-lhe a novidade, neutralizar o choque. Por isso, a fascinação da poesia de Bau-

\footnotetext{
${ }^{6}$ Nesse sentido, para Christine Buci-Glucksman o barroco se faz moderno. Ao contrário de nossa hipótese, que é a de que a modernidade que traz em si um problema de "origem", no sentido benjaminiano do termo, barroca.

${ }^{7} \mathrm{Na}$ tradução que ofereço em português: "é o potencial de estranhamento que carregam os objetos quando perdem a autoridade que deriva de seu valor de uso e que garante sua inteligibilidade tradicional, para assumir a máscara enigmática da mercadoria. [...] desse modo [o choque] teria conseguido fazer da obra veículo mesmo do inapreensível e restaurar na inapreensibilidade mesma um novo valor e uma nova autoridade. Cf. Agamben, Giorgio. Estancias. La palabra y el fantasma en la cultura occidental, tradução Tomás Segovia. Valencia: Ediciones Pre-textos, 2001: 88).
}

" (BUCI-GLUCKSMAN, C. La folie du voir. Paris: Galilée, 2002: 50.)

" (BENJAMIN, W. "Sobre alguns temas em Baudelaire". Charles Baudelaire. Um lírico no auge do capitalismo. Op. cit.: 111.)

(AGAMBEN, G. Estancias. La palabra y el fantasma en la cultura occidental. Tradução Tomás Segovia. Valencia: Ediciones Pre-textos, 2001: 88.) 
delaire pela mercadoria e pela maquiagem, desde logo, o "inexperimentável”. Agamben diz ainda nesse texto que As Flores do Mal são os provérbios do "inexperimentável". Mas o que Agamben não responde é por que esse "inexperimentável" está associado à melancolia e ao Mal e de que se trata nesse saber do Mal. Estaríamos de alguma maneira conectados àquele monstruoso "antiartístico" do barroco? O poema "O Irremediável", incluído em "Spleen e ideal", declara a impossibilidade da experiência, pois seu desejo oscila se debatendo entre o "amor" ao que é "disforme", isto é, o "inexperimentável", e "a consciência dentro do Mal", a busca por um saber que decorra da experiência.

$[\ldots]$

Um Anjo, viajante imprudente

Que ousou amar o que é disforme

Dentro de um pesadelo enorme

A debater-se na corrente

E a lutar, angústias sombrias!

Contra um fluxo mais feroz,

$[\ldots]$

Farol irônico, infernal

Archote aceso a Satanás,

Consolo e glórias sem iguais

- A consciência dentro do Mal!*

Lembremos do que Benjamin anota sobre o barroco: o saber que não decorre de uma vivência, portanto, de uma prática, é o saber do Mal. É uma referência ao saber humano que se produz fora da história moderna do Ocidente, é um saber de antes do pecado original, bem como uma maneira de reafirmá-lo, isto é, de dar-lhe uma existência. É a outra metade da arte, bem como da modernidade.

O problema do pecado original é questão que persegue Baudelaire. Os versos do poema "O Irreparável" dão prova disso:

$[\ldots]$

Como abafar este Remorso inexorável?

[...]

Como clarear um céu ao sol indiferente?

[...]

O irreparável rói com a presa maldita; 
Por isso, talvez não seja de todo impróprio dizer que a paixão floral que Baudelaire justapõe aos seus "provérbios do inexperimentável” esteja mais próxima da tradição floral do século XVII do que da do século XIX. Lily Litivak nos demonstra em Erotismo y fin de siglo o quanto o simbolismo floral e a sensualidade dos jardins foi uma unanimidade entre vários poetas desse período. Nesse topos literário a natureza serve de motivo para que o artista expresse a si mesmo, bem como expresse uma experiência erótica pessoal. No entanto, em Baudelaire não está em questão a correspondência entre uma experiência erótica pessoal e a natureza. As correspondências com a natureza são uma maneira de Baudelaire produzir uma forma poética impessoal, portanto, exterior. E o que está em questão é o limite, entendido como limiar, isto é, como soleira entre a natureza humana caída e a natureza humana divinizada. E essa é uma questão ainda a ser encarada como problema poético em outros poetas simbolistas. O poeta paranaense Dario Veloso, admirado senão por outro satanista que Paulo Leminski, ao comentar o livro de poemas Bronzes, de Júlio Perneta, publicado em 1897, vaticina: "Não sou dos que entendem que fora do íntimo ideal não há ideal, e que fora da crença íntima não há salvação [...]". E E afirma, mais adiante, que compreende, a partir de Jules Michelet, que "SATÃ é a Ciência, e afirmo, com o respeitável autor da Sorcière, que a obra de Satã 'descansa sobre três pedras eternas: a Razão, o Direito e a Natureza”." Já em Au-delà de la mélancolie, Christine Buci-Glucksman associa a história do olhar no Ocidente à história da paixão floral, é como se o motivo das flores na sua variedade histórica - desde as naturezas-mortas e das Vanitas do século XVII às flores de Manet, Monet, Van Gogh, Matisse, O’Keeffe, Warhol ou Richter - desdobrasse os motivos de um olho reflexivo e atento, aberto sobre o mundo. Buci-Glucskman completa sua análise sublinhando que a flor não é uma essência, mas sim uma metáfora e por que não uma alegoria da pintura no sentido que lhe ofereceu Vermeer. Portanto, a flor vê, e se ela vê, é porque há uma visão primeira ensaiada na flor, um saber primário que deriva da contemplação, o Mal. Porém, esse saber não se contenta em ficar apenas com o lado "inexperimentável" de todo conhecimento, ele quer passar ao outro lado, para o lado experimentável da beleza. $\mathrm{O}$ saber das coisas para além da negatividade de toda a mercadoria, para além de toda melancolia. É daí que a contemplação da natureza como soleira entre o humano e o divino pode ganhar sentido na obra de Baudelaire.
(VELOSO, Dario. "O livro". Em: CAROLLO, Cassiana Lacerda. Decadentismo e simbolismo no Brasil. Seleção e apresentação de Cassiana Carollo. Brasília: Instituto Nacional do Livro, 1980: 71)

"(Idem.) 
(BENJAMIN, W. "Sobre alguns temas em Baudelaire". Charles Baudelaire. Um lírico no auge do capitalismo. Op. cit.:133.)
(BENJAMIN, W. Origem do drama barroco alemão. Op. cit.: 69.)
Para fazer com que sua poesia sobrevivesse a ele mesmo e à história, Baudelaire destrói o valor de uso de uma simbologia do floral de sua época para encontrar nele os fósseis da paixão floral de uma pré-história moderna, mas que é também pós-histórica, e não necessariamente antimoderna. No "flowers still life" do século XVII as flores não são na realidade flores. Há uma sobreposição do pensamento religioso contra-reformista sobre a transitoriedade do humano ao da ciência natural que se dedicava a investigar as metamorfoses da natureza sobre o enfoque do declínio e da destruição. Desse saber pós-natural destrutivo, a obra Goethe é ainda a mais forte sobrevivente. E é propriamente Walter Benjamin quem irá testemunhar, isto é, colocar em ação essa sobrevivência do pós-natural como destruição, uma vez que o ensaio "As afinidades eletivas em Goethe" é citado em seu ensaio sobre Baudelaire justamente quando ele associa a reflexão do belo no poeta francês à idéia de formas primordiais. Diz Benjamin: "o belo pode ser definido como aquilo que apenas 'permanece essencialmente idêntico a si mesmo, quando velado"'. "No livro $A$ metamorfose das plantas, Goethe postula, a partir da investigação das relações entre o disseminado e o configurado, o que ele chama de "sintesis misteriosa", que elas produzem as formas primordiais, e que há que diferenciálas do que é agregado: mera conjunção de elementos díspares. Como os enigmas, as formas primordiais somente se deixam iluminar no momento do declinar de sua forma, no momento em que elas se tornam fósseis, isto é, idênticas a si mesmas, porém, veladas, escondidas sob outras formas, outros enigmas. Essa reflexão de Goethe se transforma na epígrafe do trabalho de doutorado de Benjamin, $O$ conceito de crítica de arte no romantismo alemão. Em outro livro, A teoria das cores, Goethe demonstra que, como na ciência natural que se manifesta na sua totalidade sempre em cada objeto estudado, cada obra de arte individual contém sempre a potência de toda a arte. Essa reflexão de Goethe torna-se a epígrafe do segundo livro de Walter Benjamin, sua livre-docência, Origem do drama barroco alemão. Ali Benjamin devolverá potência às reflexões de Goethe sobre as "formas primordiais", "Urformen":

A origem, portanto, não se destaca dos fatos, mas se relaciona com sua pré e pós-história. [...] A pré e a pós-história de tais essências, testemunhando que elas foram salvas ou reunidas no recinto das idéias, não são história pura, e sim história natural. A vida das obras e das formas [...] é uma vida natural. 
$\mathrm{O}$ conceito de vida natural fora desenvolvido antes por Benjamin, no ensaio de 1923, "A tarefa do tradutor", no qual ele demonstra que a vida natural de uma obra está relacionada à sobrevida dessa obra, à sua sobrevivência em outras obras. Daí que as "formas primordiais" iluminam os objetos, nunca os transformam, as formas primordiais não estão diante da arte, mas na arte, portanto, jamais podem proporcionar parâmetros, apenas potências uma vez que se encontram veladas, fossilizadas sob outras formas de vida. Diante das monstruosidades antiartísticas do barroco e da compreensão delas como "formas primordiais", interessa reportarmo-nos à função que Michel Foucault detectou em duas instâncias classificatórias nos séculos XVI e XVII:

A partir do poder do contínuo que a natureza detém, o monstro faz aparecer a diferença: esta é ainda sem lei e sem estrutura bem definida; [...] O fóssil é aquilo que deixa subsistir as semelhanças através de todos os desvios que a natureza percorreu; funciona como uma forma longínqua e aproximativa da identidade; marca um quase-caráter no mover-se do tempo.

E será motivado senão por outro pensamento que o das "formas primordiais" que Benjamin compreende o procedimento da poesia de Baudelaire das "correspondances" como "sintesis misteriosa" e ainda, como desdobramento desta leitura que ora lhes apresento, como "ponderación misteriosa”. Portanto, concluirá Benjamin em "Alguns temas em Baudelaire": "[...] As correspondances nos dizem o que devemos entender por esse véu. Pode-se considerar este último (para resumir de forma certamente ousada) o elemento reprodutor na obra de arte."*
* (FOUCAULT, Michel. As palavras e as coisas. Tradução Salma Muchail. São Paulo: Martins Fontes, 2002: 217.)

* (BENJAMIN, W. "Sobre alguns temas em Baudelaire". Charles Baudelaire. Um lírico no auge do capitalismo. Op. cit.:133) 


\section{Susana Scramim}

Susana Scramim é professora na Universidade Federal de Santa Catarina, pesquisadora do Núcleo de Estudos Literários e Culturais NELIC/ UFSC. É doutora em Teoria Literária e Literatura Comparada pela Universidade de São Paulo. Realizou estágio Pós-Doutoral na Universidade de Sevilla, em 2005, onde desenvolveu pesquisa sobre as releituras do Barroco Ibérico pela literatura latino-americana. Professora Visitante no Talen en culturen van Latijns Amerika (Departamento de Estudos de Cultura Latino-americana), da Leiden Universiteit (Universidade de Leiden), na Holanda, onde ministrou o seminário "Cultural Identity and Post-Modern Writing: the baroque effect". Organizou as edições especiais da revista outra travessia sobre Euclides da Cunha e sobre Giorgio Agamben e Georges Bataille. É autora do livro Literatura do presente: história e anacronismo dos textos (Chapecó: Ed. Argos, 2007).

Palavras-chave: As flores do mal; correspondances; Walter Benjamin; anacronismo; formas imemoriais.

\section{Resumo}

Este ensaio visa estudar as "correspondances" operadas em As flores do mal considerando sua característica de procedimento poético que testemunha uma concepção crítica simultaneamente "pré" e "pós-moderna" nos poemas ali reunidos. As "correspondances" serão consideradas na relação entre procedimentos de figuração poética e a historicidade "natural" das formas, e observadas a partir de um ponto de vista anacrônico, que, segundo Walter Benjamin, produz uma experiência poética cuja temporalidade é organizada com base na idéia de fluxo imemorial. 


\section{Abstract}

This essay proposes a critical approach on the "correspondences" in the Les Fleurs du Mal, considering their dimensions as a poetic device. The "correspondences" are considered in their relationships between poetic device and "natural" historicity of forms, and are observed from the point of view of the "anachronism" that, according Walter Benjamin, produces a poetic experience organized from an immemorial idea of flux.

\section{Résumé}

Cet article vise à étudier les "correspondances" opérées dans Les fleurs du mal en considérant leur caractéristique de démarche poétique témoignant d'une conception critique simultanément "pré" e "post-moderne" dans les poèmes du recueil. Les "correspondances" seront prises dans le rapport entre des procédés de figuration poétique et l'historicité "naturelle" des formes, et observées à partir d'un point de vue anachronique qui, selon Walter Benjamin, produit une expérience poétique dont la temporalité s'organise sur l'idée de flux immémorial.
Key words: Les Fleurs du Mal; correspondances; Walter Benjamin; anachronism; immemorial forms.

Mots-clés: Les fleurs du mal; correspondances; Walter Benjamin; anachronisme; formes immémoriales. 